\title{
Use of tricyclic antidepressants and risk of glioma: a nationwide case-control study
}

\author{
Anton Pottegård ${ }^{\star}, 1$, Luis Alberto García Rodríguez ${ }^{2}$, Lotte Rasmussen ${ }^{1}$, Per Damkier ${ }^{1,3}$, Søren Friis ${ }^{4}$ and \\ David Gaist ${ }^{5,6}$ \\ ${ }^{1}$ Clinical Pharmacology, Department of Public Health, University of Southern Denmark, Odense, Denmark; ${ }^{2}$ Centro Español \\ Investigatión Farmacoepidemiológica (CEIFE), Madrid, Spain; ${ }^{3}$ Department of Clinical Chemistry and Pharmacology, Odense \\ University Hospital, Odense, Denmark; ${ }^{4}$ Danish Cancer Society Research Center, Danish Cancer Society, Copenhagen, Denmark; \\ ${ }^{5}$ Department of Neurology, Odense University Hospital, Odense, Denmark and ${ }^{6}$ Department of Clinical Research, Faculty of \\ Health Sciences, University of Southern Denmark, Odense, Denmark
}

Background: A protective effect of tricyclic antidepressants (TCAs) against gliomas has been suggested by a small number of studies. We investigated this putative association in a nationwide setting.

Methods: Using a case-control design, we identified all patients with histologically verified glioma (cases) in Denmark between 2000 and 2012 and matched these 1:20 to population controls. Conditional logistic regression was used to estimate adjusted odds ratios (ORs) for glioma associated with long-term ( $\geqslant 3$ years) use of TCAs. Similar analyses were performed for selective serotonin reuptake inhibitors (SSRIs).

Results: We identified 3767 glioma cases and 75340 population controls. Long-term use of TCAs was inversely associated with risk of glioma (OR 0.72, 95\% Cl: 0.41-1.25). Long-term SSRI use was not associated with glioma risk (OR 0.93, 95\% Cl: 0.75-1.16).

Conclusions: Our study indicated that long-term use of TCAs may be associated with a reduced risk of glioma, however, the statistical precision was limited. A similar pattern was not observed for use of SSRIs.

Gliomas constitute about $80 \%$ of malignant brain tumours and cause significant morbidity and mortality (Ostrom et al, 2014). Although some progress has been made in identifying risk factors for glioma (Chen et al, 2011; Goodenberger and Jenkins, 2012; Ostrom et al, 2014), the aetiology remains largely unknown. Investigations of the effect of commonly used drugs on glioma risk (Walker et al, 2011; Ferris et al, 2012; Gaist et al, 2013a, b) may improve our understanding of glioma aetiology.

Laboratory studies have indicated that tricyclic antidepressants (TCAs) exert antineoplastic effects (Levkovitz et al, 2005; Jahchan et al, 2013), although the results are equivocal. Thus far, only one epidemiological study has specifically addressed the risk of glioma among users of antidepressants (Walker et al, 2011), reporting a statistically significantly reduced risk of glioma associated with repeat TCA use (odds ratio (OR) 0.59, 95\% CI: $0.42-0.81)$.
To provide further epidemiological data on the potential protective effect of TCA use against gliomas, we conducted a nationwide casecontrol study of the association between long-term use of TCA and risk of glioma. For comparison, we performed similar analyses for selective serotonin reuptake inhibitors (SSRIs).

\section{MATERIALS AND METHODS}

In a nationwide case-control study, we compared the use of TCAs among individuals with incident glioma (cases) with use among cancer-free persons (controls) to estimate ORs for glioma associated with overall or long-term TCA use.

Data sources. We used data from five Danish nationwide registries: the Danish Cancer Registry (Gjerstorff, 2011), the National

*Correspondence: Dr A Pottegård; E-mail: apottegaard@health.sdu.dk

Received 4 December 2015; revised 18 March 2016; accepted 30 March 2016; published online 26 April 2016 
Prescription Registry (Kildemoes et al, 2011), the National Patient Register (Lynge et al, 2011), a register in Statistics Denmark holding information on educational level (Baadsgaard and Quitzau, 2011), and the Civil Registration System (Pedersen, 2011). Detailed information on the included registries is provided in the Supplementary Appendix A, while codes for identification of cases, drug use, and other characteristics are provided in the Supplementary Appendix B.

Cases and controls. From the Danish Cancer Registry, we identified all individuals in Denmark with a first-time diagnosis of glioma between 1 January 2000 and 31 December 2012. The date of cancer diagnosis defined the index date. Case diagnoses were restricted to histologically verified gliomas. Exclusion criteria were age $<18$ years or $>85$ years at diagnosis, previous cancer (except non-melanoma skin cancer), and residency outside Denmark within 10 years prior to index date, ensuring at least 10 years of follow-up and a minimum of 5 years of prescription coverage (see Supplementary Appendix A).

We matched each case to 20 population controls on sex and birth year by risk-set sampling, applying the same selection criteria as for cases. Controls were assigned an index date identical to that of their corresponding case. With the nested case-control design and risk-set sampling of control participants, the calculated ORs provide unbiased estimates of the corresponding incidence rate ratios in the underlying source population.

Exposure definition. Our primary exposure was use of TCA (Anatomical Therapeutic Classification (ATC) code N06AA, see Supplementary Appendix C). We disregarded prescriptions redeemed within 1 year prior to the index date, to reduce the possibility of reverse causation (Jørgensen et al). Ever use of TCA was defined as having filled $\geqslant 1$ prescriptions for any TCA prior to index date. Ever use was further classified into current/recent use $(\geqslant 1$ prescriptions within 1-1.99 years prior to the index date) and past use $(\geqslant 1$ prescriptions $>2$ years prior to the index date).

Long-term use of TCA was defined as $\geqslant 3$ years of cumulative duration of use prior to the index date. The duration of each prescription in days was defined as the total number of defined daily doses per prescription.

Main analyses. We used conditional logistic regression to estimate ORs for glioma associated with long-term ( $\geqslant 3$ years) use of TCA. We further performed analyses according to the cumulative duration of TCA use in four categories: $<1,1-2,3-4$, and $\geqslant 5$ years. In all analyses, the reference group was never-users of TCA.

Using prescription, patient, and sociodemographic data (see Supplementary Appendices A and B), disregarding the period 1 year prior to the index date, we adjusted for several potential confounders known or suspected to be associated with risk of gliomas, including (i) use ( $\geqslant 2$ prescriptions) of statins, anti-diabetics, low-dose aspirin, non-aspirin non-steroidal antiinflammatory drugs, inhibitors of the renin-angiotensin system, antihistamines, anti-asthma drugs, oral contraceptives, and hormonal replacement therapy; (ii) history of diabetes, stroke, allergy, and asthma; and (iii) highest achieved education.

Supplementary analyses. We performed a number of pre-planned supplementary analyses.

First, we repeated the main analyses with SSRI use as the primary exposure. Further, we performed dose-response analyses for all single antidepressant agents (including non-TCAs/SSRIs) used by $>100$ controls (see Supplementary Appendix C). In these analyses, never use of SSRIs or the individual agent was used as the reference.

Second, we stratified the analyses by type of glioma, that is, glioblastoma multiforme, astrocytoma grade II and III, oligodendroglioma grade II and III, and 'other types'.
Third, we examined the influence of consistency of TCA use on glioma risk by stratifying long-term TCA use according to the presence or absence of prescription-free periods of $\geqslant 1$ year within 5 years prior to the index date.

Fourth, we examined associations for glioma with TCA use within subgroups defined by sex, age, or previous polyneuropathy. The latter was done to evaluate the potential influence of confounding by indication on the risk estimates.

Finally, we lagged drug and covariate exposure with 2 or 0 years, respectively, instead of the 1-year lag used in the main analyses.

Other. All analyses were performed using Stata Release 14.0 (StataCorp, College Station, TX, USA). The study was approved by the Danish Data Protection Agency. According to Danish law, studies based solely on register data do not require approval from an ethics review board (Thygesen et al, 2011).

\begin{tabular}{|c|c|c|}
\hline & $\begin{array}{c}\text { Cases } \\
(n=3767)\end{array}$ & $\begin{array}{c}\text { Controls } \\
(n=75340)\end{array}$ \\
\hline Age, median (IQR) & $60(49-68)$ & $60(49-68)$ \\
\hline \multicolumn{3}{|l|}{ Sex } \\
\hline Male & $2217(58.9 \%)$ & 44340 (58.9\%) \\
\hline Female & $1550(41.1 \%)$ & 31000 (41.1\%) \\
\hline \multicolumn{3}{|l|}{ Glioma subtype } \\
\hline Glioblastoma multiforme & $2353(62.5 \%)$ & NA \\
\hline Astrocytoma grade II and III & $594(15.8 \%)$ & NA \\
\hline Oligodendroglioma grade II and III & $476(12.6 \%)$ & NA \\
\hline Others & 344 (9.1\%) & NA \\
\hline \multicolumn{3}{|l|}{ Use of TCA ${ }^{a}$} \\
\hline Never use & $3630(96.4 \%)$ & $72152(95.8 \%)$ \\
\hline Ever use & $137(3.6 \%)$ & 3188 (4.2\%) \\
\hline Current/recent use & $36(0.96 \%)$ & $973(1.3 \%)$ \\
\hline Past use & $101(2.7 \%)$ & 2215 (2.9\%) \\
\hline Long-term use ( $\geqslant 3$ years) & $13(0.35 \%)$ & $373(0.50 \%)$ \\
\hline Continuous long-term use & $11(0.29 \%)$ & $292(0.39 \%)$ \\
\hline \multicolumn{3}{|l|}{ Use of SSRI ${ }^{a}$} \\
\hline Never use & $3336(88.6 \%)$ & $66118(87.8 \%)$ \\
\hline Ever use & 431 (11.4\%) & $9222(12.2 \%)$ \\
\hline Current/recent use & 207 (5.5\%) & 4043 (5.4\%) \\
\hline Past use & $224(5.9 \%)$ & 5179 (6.9\%) \\
\hline Long-term use ( $\geqslant 3$ years) & $89(2.4 \%)$ & $1932(2.6 \%)$ \\
\hline Continuous long-term use & 75 (2.0\%) & $1534(2.0 \%)$ \\
\hline \multicolumn{3}{|l|}{ Drugs } \\
\hline Statins & $513(13.6 \%)$ & $11290(15.0 \%)$ \\
\hline Anti-diabetics & $294(7.8 \%)$ & 6971 (9.3\%) \\
\hline Low-dose aspirin & $513(13.6 \%)$ & $11856(15.7 \%)$ \\
\hline NSAIDs & $1735(46.1 \%)$ & $35533(47.2 \%)$ \\
\hline $\begin{array}{l}\text { Inhibitors of the renin-angiotensin } \\
\text { system }^{\mathbf{b}}\end{array}$ & $682(18.1 \%)$ & 14442 (19.2\%) \\
\hline Antihistamines & 491 (13.0\%) & 10097 (13.4\%) \\
\hline Anti-asthma drugs & $556(14.8 \%)$ & 12044 (16.0\%) \\
\hline Oral contraceptives & 449 (11.9\%) & $9013(12.0 \%)$ \\
\hline Hormone replacement therapy & $514(13.6 \%)$ & $10984(14.6 \%)$ \\
\hline \multicolumn{3}{|l|}{ Diagnoses } \\
\hline Diabetes & $118(3.1 \%)$ & $3056(4.1 \%)$ \\
\hline Stroke & $65(1.7 \%)$ & $1452(1.9 \%)$ \\
\hline Allergy or asthma & $122(3.2 \%)$ & $2827(3.8 \%)$ \\
\hline \multicolumn{3}{|l|}{ Highest achieved education } \\
\hline Short (7-10 years) & $1302(34.6 \%)$ & 25886 (34.4\%) \\
\hline Medium (11-13 years) & $1539(40.9 \%)$ & 30365 (40.3\%) \\
\hline Long (>13 years) & $813(21.6 \%)$ & $16001(21.2 \%)$ \\
\hline Missing & $113(3.0 \%)$ & 3088 (4.1\%) \\
\hline \multicolumn{3}{|c|}{$\begin{array}{l}\text { Abbreviations: } I Q R=\text { interquartile range; } N A \text {, not applicable; } N S A I D=\text { non-steroidal anti } \\
\text { inflammatory drugs; } S S R I=\text { selective serotonin reuptake inhibitor; } T C A=\text { tricyclic antide- } \\
\text { pressant. } \\
\mathrm{a}>1 \text { year prior to the index date. }\end{array}$} \\
\hline
\end{tabular}




\section{DISCUSSION}

In this nationwide study, we found an inverse, albeit statistically non-significant, association between TCA use and risk of glioma. However, the statistical precision of our analyses was generally limited.

The main strength of our study is the use of high-quality nationwide registries, whereas the main limitation was the low number of exposed cases limiting the statistical precision and complicating interpretation of subgroup analyses.

The only previous observational study of TCA use and glioma risk reported a statistically significant reduction in glioma risk associated with the use of TCAs with an OR of 0.59 (95\% CI:, 0.42-0.81) while also showing a statistically significant dose-dependency (Walker et al, 2011). The authors also reported a null association between use of SSRI and glioma risk (OR 0.96; 95\% CI: 0.61-1.53) (Walker et al, 2011). Although with less statistical precision, our results are largely compatible with those of the study by Walker et al (2011).

Biologically plausible explanations supporting these findings appear insufficiently accounted for. Some in vitro studies suggest that antidepressants inhibit the growth of human glioma cell lines (Ishiuchi et al, 2007; Liu et al, 2015). The primary mechanism appears to be related to the overexpression of $A M P A R$ receptors in glioma tissues with TCAs acting as ligands resulting in apoptosis. Autophagy has been suggested as another mechanism of action (Jeon et al, 2011). Study conditions have been heterogeneous, but overall, fluoxetin, paroxetin, sertraline, and clomipramine have demonstrated an enhancing effect on apoptosis in human glioma cell lines (Levkovitz et al, 2005; Tzadok et al, 2010; Liu et al, 2015). No such effect could be demonstrated for imipramine or mianserine (Levkovitz et al, 2005). Other antidepressants have not been subject to comparable studies. As such, we would hypothesise that signals, if any, be present for fluoxetine, paroxetine, sertraline, and clomipramine, but not for imipramine or mianserine. No such pattern was observed (see Supplementary Results II), however, the statistical precision was low in the analyses of individual agents.

Although our findings support the hypothesised protective effect of TCAs on the development of glioma, further substantiation from association studies and elucidation of the biological rationale is required.

\section{ACKNOWLEDGEMENTS}

Morten Olesen is acknowledged for help with data management.

\section{CONFLICT OF INTEREST}

The authors declare no conflict of interest.

\section{REFERENCES}

Baadsgaard M, Quitzau J (2011) Danish registers on personal income and transfer payments. Scand J Public Health 39: 103-105.
Chen C, Xu T, Chen J, Zhou J, Yan Y, Lu Y, Wu S (2011) Allergy and risk of glioma: a meta-analysis. Eur J Neurol Off J Eur Fed Neurol Soc 18: 387-395.

Ferris JS, McCoy L, Neugut AI, Wrensch M, Lai R (2012) HMG CoA reductase inhibitors, NSAIDs and risk of glioma. Int J Cancer J Int Cancer 131: E1031-E1037.

Gaist D, Andersen L, Hallas J, Sørensen HT, Schrøder HD, Friis S (2013a) Use of statins and risk of glioma: a nationwide case-control study in Denmark. Br J Cancer 108: 715-720.

Gaist D, García-Rodríguez LA, Sørensen HT, Hallas J, Friis S (2013b) Use of low-dose aspirin and non-aspirin nonsteroidal anti-inflammatory drugs and risk of glioma: a case-control study. Br J Cancer 108: 1189-1194.

Gjerstorff ML (2011) The Danish Cancer Registry. Scand J Public Health 39: $42-45$.

Goodenberger ML, Jenkins RB (2012) Genetics of adult glioma. Cancer Genet 205: 613-621.

Ishiuchi S, Yoshida Y, Sugawara K, Aihara M, Ohtani T, Watanabe T, Saito N, Tsuzuki K, Okado H, Miwa A, Nakazato Y, Ozawa S (2007) Ca2 +permeable AMPA receptors regulate growth of human glioblastoma via Akt activation. J Neurosci 27: 7987-8001.

Jahchan NS, Dudley JT, Mazur PK, Flores N, Yang D, Palmerton A, Zmoos A-F, Vaka D, Tran KQT, Zhou M, Krasinska K, Riess JW, Neal JW, Khatri P, Park KS, Butte AJ, Sage J (2013) A drug repositioning approach identifies tricyclic antidepressants as inhibitors of small cell lung cancer and other neuroendocrine tumors. Cancer Discov 3: 1364-1377.

Jeon S-H, Kim SH, Kim Y, Kim YS, Lim Y, Lee YH, Shin SY (2011) The tricyclic antidepressant imipramine induces autophagic cell death in U-87MG glioma cells. Biochem Biophys Res Commun 413: 311-317.

Jørgensen T, Herrstedt J, Friis S, Hallas J (2012) Polypharmacy and drug use in elderly Danish cancer patients during 1996 to 2006. J Geriatr Oncol 3: $33-40$.

Kildemoes HW, Sørensen HT, Hallas J (2011) The Danish National Prescription Registry. Scand J Public Health 39: 38-41.

Levkovitz Y, Gil-Ad I, Zeldich E, Dayag M, Weizman A (2005) Differential induction of apoptosis by antidepressants in glioma and neuroblastoma cell lines: evidence for $\mathrm{p}-\mathrm{c}-J u n$, cytochrome c, and caspase-3 involvement. J Mol Neurosci 27: 29-42.

Liu K-H, Yang S-T, Lin Y-K, Lin J-W, Lee Y-H, Wang J-Y, Hu C-J, Lin E-Y, Chen S-M, Then C-K, Shen S-C (2015) Fluoxetine, an antidepressant, suppresses glioblastoma by evoking AMPAR-mediated calcium-dependent apoptosis. Oncotarget 6: 5088-5101.

Lynge E, Sandegaard JL, Rebolj M (2011) The Danish National Patient Register. Scand J Public Health 39: 30-33.

Ostrom QT, Bauchet L, Davis FG, Deltour I, Fisher JL, Langer CE, Pekmezci M, Schwartzbaum JA, Turner MC, Walsh KM, Wrensch MR, Barnholtz-Sloan JS (2014) The epidemiology of glioma in adults: a 'state of the science' review. Neuro Oncol 16: 896-913.

Pedersen CB (2011) The Danish Civil Registration System. Scand J Public Health 39: 22-25.

Thygesen LC, Daasnes C, Thaulow I, Brønnum-Hansen H (2011) Introduction to Danish (nationwide) registers on health and social issues: structure, access, legislation, and archiving. Scand J Public Health 39: 12-16.

Tzadok S, Beery E, Israeli M, Uziel O, Lahav M, Fenig E, Gil-Ad I, Weizman A, Nordenberg J (2010) In vitro novel combinations of psychotropics and anti-cancer modalities in U87 human glioblastoma cells. Int J Oncol 37: 1043-1051.

Walker AJ, Card T, Bates TE, Muir K (2011) Tricyclic antidepressants and the incidence of certain cancers: a study using the GPRD. Br J Cancer 104: 193-197.

(c) (i) (2) (2) This work is licensed under the Creative Commons cc) ${ }_{\text {BY }}$ NG SA Attribution-Non-Commercial-Share Alike 4.0 International License. To view a copy of this license, visit http:// creativecommons.org/licenses/by-nc-sa/4.0/

Supplementary Information accompanies this paper on British Journal of Cancer website (http://www.nature.com/bjc) 